\title{
Impact of partially and fully closed eaves on house entry rates by mosquitoes
}

Monicah M. Mburu ${ }^{1,2^{*}}$, Malou Juurlink¹, Jeroen Spitzen', Paula Moraga ${ }^{3}$, Alexandra Hiscox, Themba Mzilahowa ${ }^{2,4}$, Willem Takken ${ }^{1}$ and Robert S. McCann ${ }^{1,2}$

\begin{abstract}
Background: Most people infected with malaria acquire the infection indoors from mosquito vectors that entered the house through open eaves, windows and doors. Structural house improvement (e.g. closed eaves and screened windows) is an established method of reducing mosquito entry. It could be complementary to other interventions such as insecticide-treated bed nets (ITNs) for malaria control because it covers and protects all individuals in a house equally. However, when implemented at a large scale, house improvement may not be employed optimally. It is therefore critical to assess whether partial house improvement will have any effect on mosquito house entry. We investigated the effect of partial and complete eave closure on the house-entry rates of malaria vectors and other mosquitoes in southern Malawi.

Methods: The study was conducted for 25 nights in May-June 2016. Twenty-five traditional houses were modified according to five treatments: fully closed eaves, three different levels of partially closed eaves, and open eaves. All houses had fully screened windows and closed doors. Host-seeking mosquitoes were sampled inside these houses using Centers for Disease Control and Prevention (CDC) light traps. The effect of open eaves versus partial or complete eave closure on the number of mosquitoes trapped inside the house was estimated using a generalized linear mixed model fitted with Poisson distribution and a log-link function.
\end{abstract}

Results: House entry by malaria vectors was 14-times higher in houses with fully open eaves compared to houses with fully closed eaves adjusting for wall-type, number of people that slept in the house the previous night, cooking locations and presence of livestock. Houses with four small openings had 9 times more malaria vectors compared to houses with fully closed eaves. The catches of culicine mosquitoes caught in houses with fully closed eaves were not different from those caught in houses with the other treatments.

Conclusions: Closed eaves resulted in fewer malaria vectors in houses, with differences depending on the degree of eave closure. The ability of malaria vectors to locate any remaining entry points on improved houses, as demonstrated here, suggests that quality control must be an important component of implementing house improvement as an intervention. The lack of effect on culicine mosquitoes in this study could reduce acceptance of house improvement, as implemented here, by household residents due to continued nuisance biting. This limitation could be addressed through community engagement (e.g. encouraging people to close their doors early in the evenings) or improved designs.

Keywords: House improvement, Eaves, Malaria vectors, House entry, Anopheles, Culicines, Vector control

\footnotetext{
* Correspondence: monicahmirai@yahoo.com

${ }^{1}$ Wageningen University and Research, Wageningen, The Netherlands

${ }^{2}$ College of Medicine, University of Malawi, Zomba, Malawi

Full list of author information is available at the end of the article
}

(c) The Author(s). 2018 Open Access This article is distributed under the terms of the Creative Commons Attribution 4.0 International License (http://creativecommons.org/licenses/by/4.0/), which permits unrestricted use, distribution, and reproduction in any medium, provided you give appropriate credit to the original author(s) and the source, provide a link to the Creative Commons license, and indicate if changes were made. The Creative Commons Public Domain Dedication waiver (http://creativecommons.org/publicdomain/zero/1.0/) applies to the data made available in this article, unless otherwise stated. 


\section{Background}

Malaria continues to place a heavy burden on communities living in malaria endemic areas, in spite of promising declines in malaria globally due to the use of insecticide-treated bed nets (ITNs), indoor residual spraying (IRS) and effective drug therapy [1]. In endemic regions of Africa, where $90 \%$ of cases and deaths from malaria occur [2], indoor biting by malaria vectors still plays a prominent role in malaria transmission [3-5] and the structural design of houses affects the entry of malaria vectors into residences. Houses with modern features (e.g. closed eaves, screened doors and windows, and ceilings) can provide the first line of defense against bites from infected malaria vector mosquitoes, whereas houses without these features have been associated with increased numbers of mosquitoes indoors [6-8] and higher levels of malaria [912]. Open eaves are significant entry points into houses for malaria vector species in Africa [13-15] and are therefore recognized as a risk factor for malaria.

Most studies looking at house design and mosquito entry (or malaria) have been observational studies of incremental improvements in house design that occur coincidentally with socioeconomic improvements over time [10]. In addition to those studies, others have tested the effect of deliberate structural modifications, also known as house improvement, as a direct intervention to block mosquito entry using materials such as netting, papyrus reeds, sand, rubble and concrete. These studies have associated house improvement with fewer mosquitoes entering homes [16-18] and reduced anaemia prevalence in children [16].

Modern house features have been viewed favourably by residents because of their perception that these features reduce mosquito bites $[17,19-21]$, with the primary concerns being the costs of these features and the potential for increased indoor temperatures [17, 19]. Additional benefits of house improvement as an intervention against malaria include: equal protection is offered to all individuals in a house, no daily action from the end user is required, it is technologically simple and it does not require insecticides in principle.

These advantages, together with the spread of insecticide resistance threatening the efficacy of ITNs and IRS $[22,23]$, have led to a renewed interest in the broad concept of house improvement as an intervention and a need to address key questions about specific aspects of the intervention related to the effectiveness of particular features, safety, acceptability and implementation [24, 25]. As with any health intervention, measuring the percentage of the population effectively covered by house improvement will be important for understanding the effectiveness of the intervention in both trial settings [26] and on a larger scale (e.g. as programmes implement house improvement at a district or national scale). Here, we refer to the
malERA Consultative Group on Health Systems and Operational Research and their definition of effective coverage, which goes beyond simple access to an intervention to also include provider compliance and client adherence $[27,28]$. In the context of house improvement, compliance could be measured in terms of the number and size of any remaining gaps in the housing structure following implementation. While the goal of implementation would be to leave zero gaps for mosquito entry, in real-world settings this would not be the case for $100 \%$ of houses with access to house improvement. Therefore, it will be important to understand the extent to which houses with remaining gaps for mosquito entry following implementation of these modifications would still provide any effective protection from mosquito bites compared to fully improved houses. The aim of this study was to assess differences in partial or complete closure of the eaves on house-entry rates by anopheline and culicine mosquitoes in a randomized field experiment.

\section{Methods \\ Study site}

The study was conducted in Chikhwawa District, southern Malawi, which lies along the lower Shire valley. This area experiences a single rainy season from November through to April. The main malaria vectors prevalent in the region are Anopheles gambiae (s.s.), An. funestus and An. arabiensis [29, 30]. Malaria transmission occurs throughout the year with rates intensifying during the rainy season. Malaria parasitemia in children under five years of age in this region varies seasonally between 11-40\% [31].

Four neighbouring villages in Chikhwawa District (Fombe, Jacobo I, Jacobo II and Semu) were identified for the study (Fig. 1), allowing for random selection of houses separated by a distance of $25 \mathrm{~m}$ away from each other. The combined population of the villages was 4740 (personal communication, secretary-group village head). The area is relatively flat (i.e. little topographic relief), with two seasonal streams. Farming subsistence crops and small-scale cash crops is the primary means of occupation in the study area. Houses in the selected villages are typical for the region. The general house design consists of four walls in a rectangular arrangement with a two-sided roof oriented along the long axis of the house (Fig. 2). House walls are typically constructed with either sun-dried or fire-baked bricks, and roofs are made with either grass thatch or corrugated sheet metal. Most houses have one door, two to four square windows, and either open or closed eaves.

\section{House selection}

The study included 25 houses. The local leaders (i.e. village chiefs) provided a list of 100 houses across the four villages separated by a distance of $\geq 25 \mathrm{~m}$ that fit the 


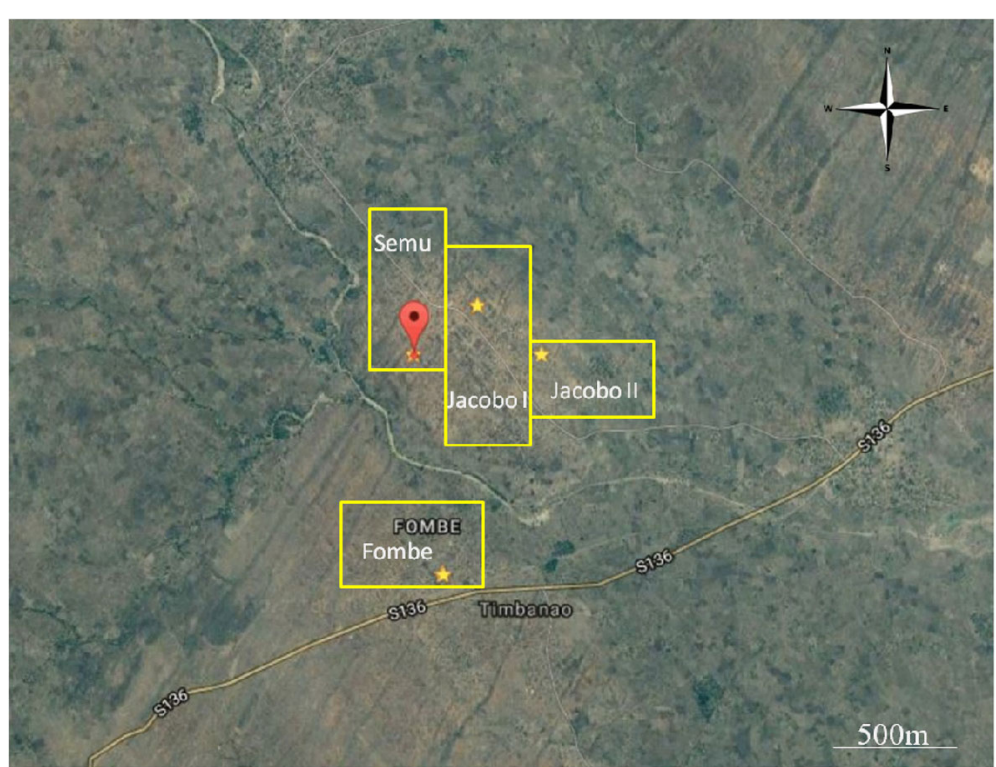

Fig. 1 Geo-location of the four villages selected for the study. Fombe: 16.06962496, 34.73430784; Jacobo I: 16.0532887, 34.7365262; Jacobo II: 16.05628311, 34.74051196; Semu: 16.05625729, 34.73250272

following criteria: open eaves, open windows, gaps around the doors, and grass thatched roofs. From these, twenty-five houses were randomly selected for enrolment into the study ( 6 from Fombe, 7 from Jacobo I, 7 from Jacobo II, and 5 from Semu).Prior to enrolment, we applied further inclusion criteria such that every house would be at least $20 \mathrm{~m}$ away from cattle sheds and within a range of $100 \mathrm{~m}$ from any mosquito breeding habitat. The houses that did not meet the inclusion criteria were replaced with the nearest neighbouring house that met all inclusion criteria. The geo-location of each house was recorded at enrolment.

\section{Treatments}

The five treatments in this study were: fully closed eaves, eaves with a single $5 \times 1 \mathrm{~cm}$ opening (hereafter referred as a single small opening), eaves with four $5 \times 1 \mathrm{~cm}$

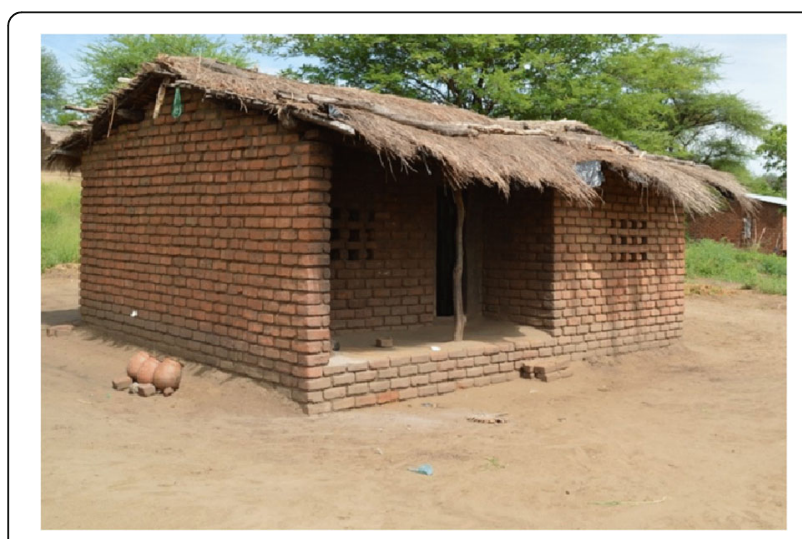

Fig. 2 Photograph of a typical house in the study area openings (hereafter referred as four small openings), eaves with two long sides open and houses in which the eaves were open on all four sides (Fig. 3). Treatments were assigned randomly to each house using a random number generator in Microsoft Excel, with five houses being assigned to each treatment. For all 25 houses, all the gaps in walls were closed with muddy soil, gaps in the doors were closed with wooden planks and windows were closed with wire gauze. Small apertures between the window frame and the wall were filled in with mud. For houses with partial and complete eave closure, a combination of bricks and muddy soil were used for eave closure. Local builders and carpenters were hired to perform the house modifications which were checked for quality by the researchers at completion. The

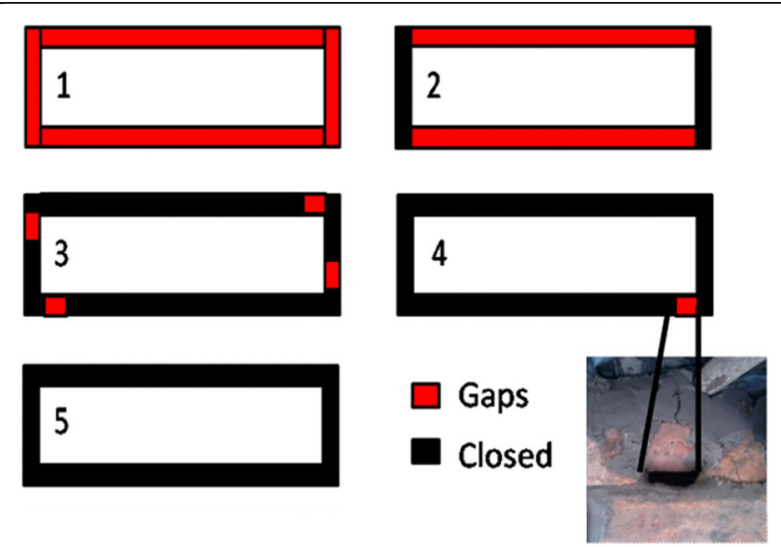

Fig. 3 Design of the five treatments assigned to the sets of five houses 
householders provided muddy soil, while the researchers provided the wire gauze for screening the windows and some bricks to close the larger openings. From our observations, the grass thatched roofs were intact, with the exception of one house where the roof had some openings. The owner of this house repaired the roof by filling in the openings with more grass.

\section{Mosquito sampling}

Mosquito sampling was carried out for four nights a week for a total of 25 nights from 12 May to 24June 2016. Centers for Disease Control and Prevention (CDC) light traps were used to sample the mosquitoes inside all houses. The traps were powered by $6 \mathrm{~V}$ batteries and operated from 17:00 h (15 min before sunset at that time of year) until 7:00 h (1 hour after sunrise). In each house, the trap was hung with the fan at $150 \mathrm{~cm}$ above the ground, at the foot end of a bed in which a person was sleeping under a bed net [32,33]. The bed nets were owned by the household. Every morning after a night of sampling, chloroform was used to immobilize the mosquitoes caught in the traps. The mosquitoes were then transferred into an Eppendorf tube containing a silica gel desiccant, and transported to the laboratory for morphological identification.

During mosquito collections, brief interviews were conducted with householders to obtain data on house parameters such as the number of people that occupied the house the previous night, livestock that stayed within $20 \mathrm{~m}$ of the house the previous night, wall type, floor type, door type and cooking locations. The following represent the categorizations: door type as wood and reed; floor type as dirt/mud/dung/sand; wall type as sun dried bricks and fire baked bricks; cooking location as inside the house, on the veranda, outside but within $2 \mathrm{~m}$ of the house and outside more than $2 \mathrm{~m}$ away from the house. Data were recorded on a tablet computer using Open Data Kit [34].

\section{Mosquito identification}

All mosquitoes were identified morphologically as either anophelines or culicines. Anophelines were further classified as either Anopheles gambiae (s.l.), An. funestus or An. coustani using the dichotomous key published by Gillies \& Coetzee [35]. There was no further classification of the culicines beyond the subfamily level. Females from the $A n$. gambiae (s.l.) species complex were further identified to species level using polymerase chain reaction (PCR) [36].

\section{Data analysis}

The effect of eave closure on the number of mosquitoes caught indoors was tested using a generalized linear mixed model fitted with a Poisson distribution and a log-link function. House identification number was included as a random effect in the model to account for the repeated measures by house. The kind of livestock that stayed within $20 \mathrm{~m}$ of the house the previous night, the cooking location, wall type and the number of people who slept in the house the previous night were included as covariates in the model. Livestock comprised of cattle, goats, sheep, chicken and pigs. Sheep and pigs were excluded from the analysis because of the low number of houses with either animal $(\leq 6)$. Similarly, floor and door types were excluded from the analysis because all the floors were made of mud; doors were made of wood in 24 houses while in the remaining house the door was made of reed. All analyses were performed using $\mathrm{R}$, version 3.3 . The primary outcome was the number of female malaria mosquitoes (hereafter referred as anophelines) caught with a CDC light trap per house, per night. Due to the low number of anophelines caught, count data for all anopheline species were pooled per treatment and day for statistical analysis. Secondary outcomes were the number of culicine females and the number of culicine males caught per house, per night. Fully closed eaves served as the reference in our analysis. Pairwise comparisons were performed with the Dunnett's test to compare each of the treatments to the reference treatment, fully closed eaves.

\section{Results}

Combined across all treatments, a total of 777 mosquitoes were collected over 625 trap-nights. Of these, 48 were female anophelines, 6 were male anophelines, 466 were female culicines, 248 were male culicines and 9 were unidentifiable. Of the female anophelines, 47 were An. gambiae (s.l.) and one An. coustani. Thirty-six and two of the female An. gambiae (s.l.) mosquitoes were identified to species level as An. arabiensis and An. gambiae (s.s.), respectively. The remainder $(n=9)$ could not be identified further because they failed to amplify. Abdominal status of the female anophelines included: unfed, $85.42 \%(n=41)$; and fed, $14.58 \%(n=7)$. No gravid or semi-gravid malaria vectors were caught. Abdominal status of female culicine mosquitoes trapped included: unfed, $97.21 \%(n=453)$; fed, $2.58 \%(n=12)$; and semi gravid, $0.21 \%(n=1)$.

The catches of female anophelines per treatment were: fully closed eaves, $4.16 \%(n=2)$; eave with a single small opening, $12.5 \%(n=6)$; eave with four small openings, $27.08 \%(n=13)$; eave with two long sides open, $12.5 \%$ ( $n$ $=6$ ); and open eaves: $43.75 \%(n=21)$. Catches in houses with fully closed eaves were significantly lower than catches in houses with four small openings (Risk ratio, $\mathrm{RR}=8.83,95 \% \mathrm{CI}: 1.16-67.14, Z=2.105, P=0.035)$, and with completely open eaves $(\mathrm{RR}=14.16,95 \% \mathrm{CI}$ : 2.05-97.91, $Z=2.687, P=0.007)$. Catch sizes of female anophelines caught in houses with fully closed eaves were similar to those in houses with a single small 
opening in the eave ( $\mathrm{RR}=4.38,95 \% \mathrm{CI}: 0.59-32.46, Z=$ $1.444, P=0.149)$ and two long sides open $(\mathrm{RR}=5.41$, 95\% CI: $0.72-40.40, Z=1.645, P=0.10$ ) (Fig. 4). Pairwise comparisons between houses with fully open eaves and fully closed eaves showed that the female anopheline catches were different $(Z=2.687$, Adjusted $P=0.022)$.

The catches of female culicine mosquitoes per treatment were: fully closed eaves, $15.02 \%(n=70)$; eave with a single small opening, $12.66 \%(n=59)$; eave with four small openings, $25.11 \%(n=117)$; eave with two long sides open, $21.67 \%(n=101)$; and open eaves, $25.54 \%$ ( $n$ =119). Catch sizes of female culicines in houses with fully closed eaves were similar to those in houses with a single small opening in the eave $(R R=0.86,95 \% \mathrm{CI}$ : $0.40-1.88, Z=-0.371, P=0.711)$, fully open eaves (RR = 1.14, 95\% CI: $0.52-2.52, Z=0.333, P=0.739$ ), four small openings $(\mathrm{RR}=1.17,95 \% \mathrm{CI}: 0.52-2.62, Z=0.377, P=$ $0.706)$ and two long sides open (RR $=1.28,95 \% \mathrm{CI}: 0.60-$ 2.75, $Z=0.637, P=0.524$ ) (Fig. 5). Pairwise comparisons did not provide evidence that catch sizes of female culicines caught in houses with fully closed eaves were different from those caught in houses with a single small opening in the eave $(Z=-0.371$, Adjusted $P=0.987)$, fully open eaves $(Z=0.333$, Adjusted $P=0.991)$, four small openings $(Z=0.377$, Adjusted $P=0.986)$ and two long sides open $(Z=0.637$, Adjusted $P=0.915))$.

The proportions of male culicine mosquitoes caught per treatment were: fully closed eaves, $18.95 \%(n=47)$; eave with a single small opening, $6.85 \%(n=17)$; eave with four small openings, $29.44 \%(n=73)$; eave with two long sides open, $8.06 \%(n=20)$; and open eaves, $36.69 \%$ $(n=91)$. There was no evidence to indicate a significant difference between catch sizes of male culicine mosquitoes in houses with fully closed eaves and houses with other treatments. Pairwise comparison showed that catch sizes of male culicine mosquitoes in houses with fully closed eaves were similar to those in houses with an eave that had one small opening $(Z=-1.135$, Adjusted $P=0.609)$, two long sides open $(Z=-0.884$, Adjusted $P=0.785)$, four small openings $(Z=-0.370$, Adjusted $P=0.988)$ and fully open eaves $(Z=0.040$, Adjusted $P=1.0$ ) (Fig. 6).

Wall type did not have an effect on the number of female anophelines $(\mathrm{RR}=0.57,95 \% \mathrm{CI}: 0.11-2.86, Z=$ -0.681, $P=0.496$ ) but the presence of chickens and the number of people who slept in the house the previous night were significantly and positively associated with catches of female anophelines $(\mathrm{RR}=4.15,95 \% \mathrm{CI}$ : -2.04-8.42, $Z=3.938, P=0.001$ and $\mathrm{RR}=1.27,95 \% \mathrm{CI}$ : $1.03-1.56, Z=2.263, P=0.024$, respectively) (Table 1 ). The number of people that slept in the house the previous night ranged from one to eight (mean $\pm \mathrm{SE}, 3.41 \pm$ 0.063). The presence of goats near a house was negatively associated with female culicine catches $(\mathrm{RR}=0.70$, 95\% CI: $0.52-0.94, Z=-2.385, P=0.017)$. Catches of female culicines in houses where people cooked outside, $2 \mathrm{~m}$ away from the house, were different from those in houses where people cooked on the veranda $(R R=0.63$, 95\% CI: $0.46-0.87, Z=-2.816, P=0.005)$, but similar to those where people cooked within $2 \mathrm{~m}$ of the house (RR $=0.80$, 95\% CI: $0.62-1.02, Z=-1.819, P=0.069)$ and inside the house $(\mathrm{RR}=1.46,95 \% \mathrm{CI}: 0.98-2.17, Z=1.841$,

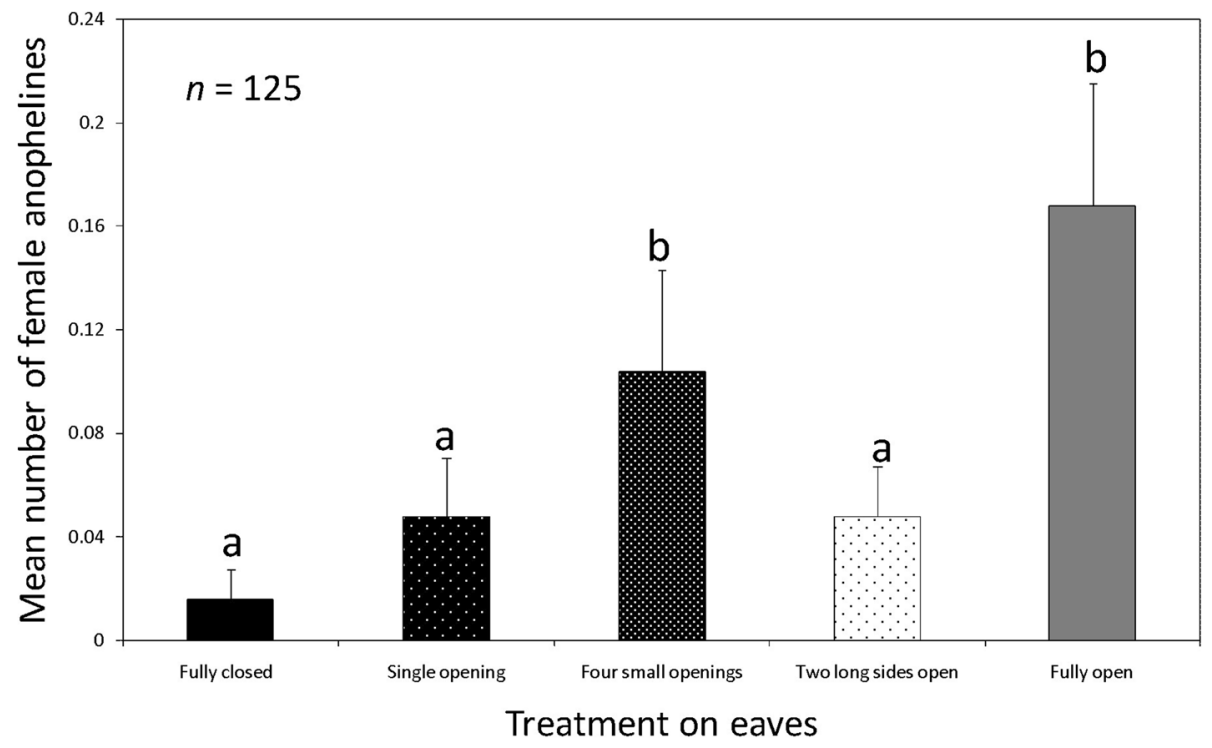

Fig. 4 Mean number of female anophelines caught indoors with CDC light traps in houses where eaves were fully closed, had a single small opening, four small openings and fully open. Bars with different letters denote significant differences in the number of mosquitoes trapped. $n=$ 125 trap nights for each treatment 


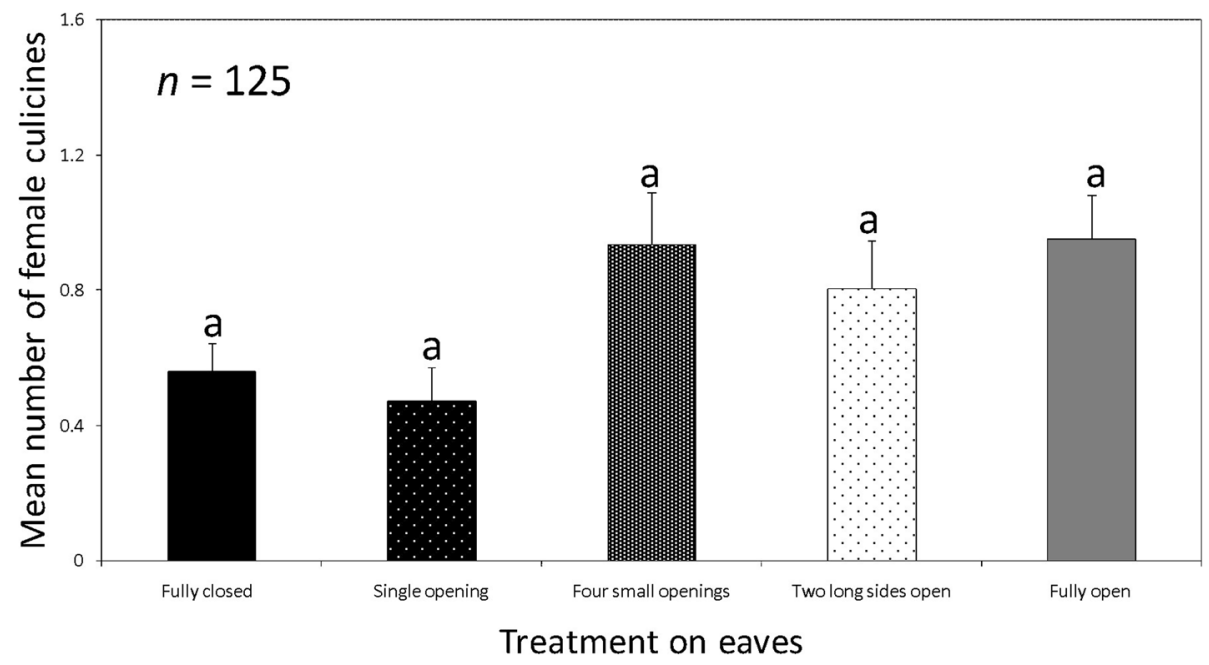

Fig. 5 Mean number of female culicines caught indoors with CDC light traps in houses where eaves: were fully closed, had a single small opening, four small openings and fully open. Bars with same letters denote similarities in the number of mosquitoes trapped. $n=125$ trap nights for each treatment

$P=0.066)$. The presence of chickens was negatively associated with the male culicine catches $(\mathrm{RR}=0.56,95 \%$ CI: $0.32-0.99, Z=-2.002, P=0.045)$ (Table 1 ).

\section{Discussion}

Houses with fully closed eaves had reduced rates of house entry by anopheline mosquitoes compared to houses with fully open eaves, similar to findings from other regions in Africa $[8,16,37]$. The reduced number of anophelines indoors suggests that a house improvement package that includes fully closed eaves could serve as an effective malaria intervention by reducing vector-human contact. Houses with fully closed eaves also had fewer malaria mosquitoes than houses with four small openings in the eaves, indicating that the latter group of houses would not provide the same level of protection against bites from malaria vectors as would houses with fully closed eaves. Malaria vectors were likely able to locate the small gaps in the eaves (i.e. the experimental sub-optimal modifications) due to the concentration of airflow and host odours emanating through such small gaps [18]. In fact, the ability of mosquitoes to readily find these holes is being exploited by studies looking

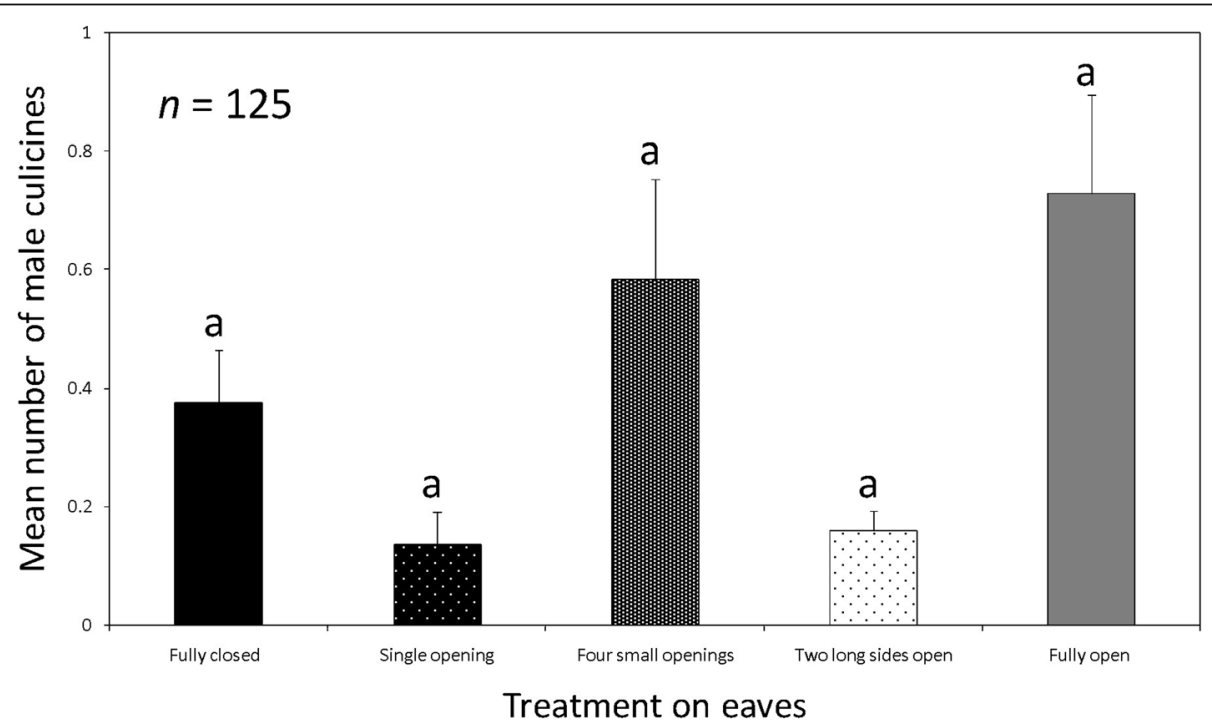

Fig. 6 Mean number of male culicines caught indoors with CDC light traps in houses where eaves: were fully closed, had a single small opening, four small openings and fully open. Bars with same letters denote similarities in the number of mosquitoes trapped. $n=125$ trap nights for each treatment 
Table 1 Effect of treatment, livestock, cooking locations, wall type and the number of people that slept in the house the previous night on the catch sizes of anophelines and culicines. The risk ratios (RR) and 95\% confidence intervals (Cl) are shown

\begin{tabular}{|c|c|c|c|c|c|c|}
\hline \multirow[t]{2}{*}{ Treatment } & \multicolumn{2}{|c|}{ Female anophelines } & \multicolumn{2}{|c|}{ Female culicines } & \multicolumn{2}{|c|}{ Male culicines } \\
\hline & $\mathrm{RR}$ & $95 \% \mathrm{Cl}$ & $\mathrm{RR}$ & $95 \% \mathrm{Cl}$ & $\mathrm{RR}$ & $95 \% \mathrm{Cl}$ \\
\hline Open eaves & 14.16 & $2.05-97.91$ & 1.14 & $0.52-2.52$ & 1.03 & $0.21-5.12$ \\
\hline Eaves with two long sides open & 5.41 & $0.72-40.40$ & 1.28 & $0.60-2.75$ & 0.49 & $0.10-2.37$ \\
\hline Eaves with four small openings & 8.83 & $1.16-67.14$ & 1.17 & $0.52-2.62$ & 0.73 & $0.14-3.82$ \\
\hline Eaves with a single small opening & 4.38 & $0.59-32.46$ & 0.86 & $0.40-1.88$ & 0.40 & $0.08-1.94$ \\
\hline Fully closed eaves & Ref & - & Ref & - & Ref & - \\
\hline People that slept in the house the previous night & 1.27 & $1.03-1.56$ & 1.07 & $0.99-1.15$ & 0.98 & $0.90-1.07$ \\
\hline Cow & 0.46 & $0.10-2.15$ & 1.29 & $0.96-1.73$ & 0.68 & $0.44-1.05$ \\
\hline Goat & 1.16 & $0.49-2.77$ & 0.70 & $0.52-0.94$ & 1.04 & $0.70-1.55$ \\
\hline Chicken & 4.15 & $2.04-8.42$ & 0.95 & $0.69-1.32$ & 0.56 & $0.32-0.99$ \\
\hline Cooking inside the house & 2.20 & $0.66-7.36$ & 1.46 & $0.98-2.17$ & 0.98 & $0.52-1.85$ \\
\hline Cooking on the veranda & 2.34 & $0.78-7.05$ & 0.63 & $0.46-0.87$ & 0.85 & $0.52-1.39$ \\
\hline Cooking outside, within $2 \mathrm{~m}$ of the house & 1.04 & $0.43-2.50$ & 0.80 & $0.62-1.02$ & 1.13 & $0.80-1.60$ \\
\hline Cooking outside, away from $2 \mathrm{~m}$ of the house & Ref & - & Ref & - & Ref & - \\
\hline Wall type fire baked bricks & 0.57 & $0.11-2.86$ & 1.83 & $0.89-3.75$ & 1.73 & $0.42-7.13$ \\
\hline Wall type sun-dried bricks & Ref & - & Ref & - & Ref & - \\
\hline
\end{tabular}

Abbreviation: Ref reference

at the impact of eave tubes on mosquito populations, whereby small sections of PVC tubing fitted with electrostatic netting that is treated with powdered insecticide or entomopathogenic fungi are inserted along closed eaves $[38,39]$. Small, uncovered openings in the eaves, such as those used as experimental treatments in the current study, may reduce the effectiveness of house improvement as a malaria intervention because malaria mosquitoes would still find their way into the house [40].

While fully-closed eaves clearly reduced the number of mosquitoes in the house, we still collected a few malaria vectors, and a considerable number of culicines, in those houses. The most probable explanation is that the mosquitoes entered through the doors [15]. While the doors on all of the houses were modified so that mosquitoes could not enter when the doors were closed, we could not control when the doors were closed. Many residents shut their doors late in the evening, facilitating the entry of mosquitoes, especially for crepuscular species. Further research is needed into the behaviour of mosquitoes around doors, and the effect of door modifications for vector-borne disease control.

The study was carried out in traditional houses spread across four villages (about $2 \mathrm{~km}$ ) allowing for comparisons among different levels of eave closure under natural conditions. While inclusion criteria were used to increase comparability among the houses, we included in our analysis additional factors that may have influenced the entry of mosquitoes into houses. Similar to previous studies, the number of people who slept in the house the previous night was associated with significantly higher numbers of female malaria vectors indoors $[41-$ 43]. In the current study, the presence of chickens within $20 \mathrm{~m}$ of the house was also associated with more female anophelines indoors, most of which were Anopheles arabiensis. This concurs with the findings of a semi-field study using chicken odour in Kenya [44], but differs with the findings of Jaleta et al. [45], who found that chickens or chicken volatiles reduced the catches of female An. arabiensis mosquitoes.The relationship between chicken odours and anopheline mosquitoes warrants further investigation.

Presence of goats and cooking on the veranda was associated with reduced female culicines. Interestingly, cooking on the veranda was also associated with reduced male culicine catches. Male mosquitoes feed on sugar and do not seek hosts for blood, but this factor was also associated with the female culicines. It is possible that the males could have been using these odour cues to locate likely presence of female culicines, an area that needs further investigation.

The relatively low number of mosquitoes collected during this study can probably be attributed to two factors. First, the rainy season prior to the study (November 2015 to April 2016) was relatively dry, with drought conditions throughout the region, and Chikhwawa District specifically receiving extremely below average rainfall [46]. Additionally, the National Malaria Control Programme in Malawi conducted a mass distribution of ITNs in April 2016. Both factors likely reduced the mosquito populations in the study area. 
Observational studies assessing the impact of housing on malaria have consistently found that people living in houses with modern features, such as closed eaves, have lower odds of malaria infection [24], even when accounting for ITN use [47].These findings have increased international interest in house improvement as a deliberate intervention against malaria [24]. House improvement covers and protects all individuals sleeping in a house equally, and its impact should not be affected by insecticide resistance. Still, observational studies are considered low-quality evidence with a high risk of bias. An ongoing trial in the Gambia aims to assess the impact of house improvement on the incidence of clinical malaria using a randomised design [48]. An ongoing cluster randomised trial in Malawi is evaluating the impact of house improvement, using a community-led implementation approach, on malaria transmission [26]. The results of the current study indicate that the quality of eave closure will be one of the important coverage indicators for understanding the effects of house improvement in these ongoing trials.

\section{Conclusions}

Our study adds to the evidence that house improvement, including fully closed eaves, reduces the number of malaria vectors indoors and, therefore, shows promise as a complementary tool for malaria control. While further research is necessary to understand the behaviour of malaria vectors around house entry points, the results of this study demonstrate the ability of malaria vectors to locate any remaining entry points on improved houses, suggesting that quality control must be an important component of implementing house improvement as an intervention [2]. The lack of effect on culicine mosquitoes in this study could reduce acceptance of house improvement, as implemented here, by household residents due to continued nuisance biting. This limitation could be addressed through community engagement (e.g. encouraging people to close their doors early in the evenings) or improved designs.

\section{Abbreviations}

ITNs: Insecticide-treated bed nets; IRS: Indoor residual spraying; CDC: Centers for Disease Control and Prevention

\section{Acknowledgements}

We acknowledge the local leaders and residents of Fombe, Semu, Jacobo I and II for allowing us to work in their houses and their cooperation. Michael Chipeta is thanked for valuable discussions on data analysis. We thank laboratory of Blantyre Malaria Project (BMP) where we did the molecular identification of female anophelines. We also extend our thanks to Majete Malaria Project (MMP) team.

\section{Funding}

The study was funded by Dioraphte Foundation, the Netherlands. The content is solely the responsibility of the authors and does not necessarily represent the official views of the funders.

Availability of data and materials

The datasets for this study are available upon a reasonable request.

\section{Authors' contributions}

$\mathrm{MM}, \mathrm{RM}$ and $\mathrm{WT}$ conceived the study design. MJ and MM did the data collection. JS, TM, RM and WT supervised the study. MM, RM and PM performed the data analysis. All authors contributed to writing the manuscript. All authors read and approved the final manuscript.

\section{Ethics approval and consent to participate}

This study complies with the principles described in Declaration of Helsinki. This study was approved by the College of Medicine Research and Ethics committee in Malawi (proposal number P.03/16/1901). Written permission to conduct the study was provided by the District Health Officer of Chikhwawa district, south Malawi. The purpose and procedures of the study were explained in the local language, Chichewa, to local leaders and householders of the four villages and participating household heads and members. Households were only enrolled in the study after providing written consent prior to the start of the study. An impartial witness was present in cases where the head of the household was illiterate.

\section{Consent for publication}

Not applicable

Competing interests

The authors declare that they have no competing interests.

\section{Publisher's Note}

Springer Nature remains neutral with regard to jurisdictional claims in published maps and institutional affiliations.

\section{Author details}

${ }^{1}$ Wageningen University and Research, Wageningen, The Netherlands. ${ }^{2}$ College of Medicine, University of Malawi, Zomba, Malawi. ${ }^{3}$ Centre for Health Informatics, Computing and Statistics (CHICAS), Lancaster Medical School, Lancaster University, Lancaster, UK. ${ }^{4}$ MAC Communicable Diseases Action Centre, College of Medicine, Blantyre, Malawi.

Received: 22 January 2018 Accepted: 25 June 2018

Published online: 03 July 2018

\section{References}

1. Bhatt S, Weiss DJ, Cameron E, Bisanzio D, Mappin B, Dalrymple U, et al. The effect of malaria control on Plasmodium falciparum in Africa between 2000 and 2015. Nature. 2015;526:207-11.

2. World Health Organization. World Malaria Report. 2017. http://wwwwhoint/ malaria/publications/world-malaria-report-2017/en/.

3. Killeen GF, Masalu JP, Chinula D, Fotakis EA, Kavishe DR, Malone D, et al. Control of malaria vector mosquitoes by insecticide-treated combinations of window screens and eave baffles. Emerg Infect Dis. 2017;23:782.

4. Bayoh MN, Walker ED, Kosgei J, Ombok M, Olang GB, Githeko AK, et al. Persistently high estimates of late night, indoor exposure to malaria vectors despite high coverage of insecticide treated nets. Parasit Vectors. 2014:7:380.

5. Huho B, Briët O, Seyoum A, Sikaala C, Bayoh N, Gimnig J. etal. Consistently high estimates for the proportion of human exposure to malaria vector populations occurring indoors in rural Africa. Int J Epidemiol. 2013;42:235-47.

6. Mutuku FM, King CH, Mungai P, Mbogo C, Mwangangi J, Muchiri EM, et al. Impact of insecticide-treated bed nets on malaria transmission indices on the south coast of Kenya. Malar J. 2011:10:356.

7. Lindsay SW, Jawara M, Paine K, Pinder M, Walraven GEL, Emerson PM. Changes in house design reduce exposure to malaria mosquitoes. Tropical Med Int Health. 2003;8:512-7.

8. Ogoma SB, Lweitoijera DW, Ngonyani H, Furer B, Russell TL, Mukabana WR, et al. Screening mosquito house entry points as a potential method for integrated control of endophagic filariasis, arbovirus and malaria vectors. PLoS Negl Trop Dis. 2010;4:e773.

9. Lindsay SW, Emerson PM, Charlwood JD. Reducing malaria by mosquitoproofing houses. Trends Parasitol. 2002;18:510-4.

10. Tusting LS, Ippolito MM, Willey BA, Kleinschmidt I, Dorsey G, Gosling RD. The evidence for improving housing to reduce malaria: a systematic review and meta-analysis. Malar J. 2015;14:209. 
11. Wanzirah H, Tusting LS, Arinaitwe E, Katureebe A, Maxwell K, Rek J, et al. Mind the gap: house structure and the risk of Malaria in Uganda. PLoS One. 2015;10:e0117396.

12. Ghebreyesus T, Haile M, Witten K, Getachew A, Yohannes M, Lindsay S. Household risk factors for malaria among children in the Ethiopian highlands. Trans R Soc Trop Med Hyg. 2000;94:17-21.

13. Lindsay $S$, Snow $R$. The trouble with eaves; house entry by vectors of malaria. Trans R Soc Trop Med Hyg. 1988;82:645-6.

14. Snow WF. Studies of house-entering habits of mosquitoes in The Gambia, West Africa: experiments with prefabricated huts with varied wall apertures. Med Vet Entomol. 1987;1:9-21.

15. Njie M, Dilger E, Lindsay SW, Kirby MJ. Importance of eaves to house entry by anopheline, but not culicine, mosquitoes. J Med Entomol. 2009;46:505-10.

16. Kirby MJ, Ameh D, Bottomley C, Green C, Jawara M, Milligan PJ, et al. Effect of two different house screening interventions on exposure to malaria vectors and on anaemia in children in The Gambia: a randomised controlled trial. Lancet. 2009;374:998-1009.

17. Atieli H, Menya D, Githeko A, Scott T. House design modifications reduce indoor resting malaria vector densities in rice irrigation scheme area in western Kenya. Malar J. 2009:8:108.

18. Kampango A, Bragança M, de Sousa B, Charlwood JD. Netting barriers to prevent mosquito entry into houses in southern Mozambique: a pilot study. Malar J. 2013;12:99.

19. Ogoma SB, Kannady K, Sikulu M, Chaki PP, Govella NJ, Mukabana WR, et al. Window screening, ceilings and closed eaves as sustainable ways to control malaria in Dar es Salaam, Tanzania. Malar J. 2009;8:221.

20. Kirby MJ, Bah P, Jones $\mathrm{COH}$, Kelly AH, Jasseh M, Lindsay SW. Social acceptability and durability of two different house screening interventions against exposure to malaria vectors, Plasmodium falciparum infection, and anemia in children in The Gambia, West Africa. Am J Trop Med Hyg. 2010;83:965-72.

21. von Seidlein L, Ikonomidis K, Mshamu S, Nkya TE, Mukaka M, Pell C, et al. Affordable house designs to improve health in rural Africa: a field study from northeastern Tanzania. Lancet Planet Health. 2017:1:e188-99.

22. Kisinza WN, Nkya TE, Kabula B, Overgaard HJ, Massue DJ, Mageni Z, et al. Multiple insecticide resistance in Anopheles gambiae from Tanzania: a major concern for malaria vector control. Malar J. 2017;16:439

23. Hemingway J, Ranson H, Magill A, Kolaczinski J, Fornadel C, Gimnig J, et al. Averting a malaria disaster: will insecticide resistance derail malaria control? Lancet. 2016;387:1785-8.

24. Tusting LS, Willey B, Lines J. Building malaria out: improving health in the home. Malar J. 2016;15:320

25. VectorControlWorkingGroup. RollBackMalaria. Consens Statement on housing and malaria. Geneva: Roll Back Malaria Housing and Malaria Work Stream; 2015.

26. McCann RS, van den Berg H, Diggle PJ, van Vugt M, Terlouw DJ, Phiri KS, et al. Assessment of the effect of larval source management and house improvement on malaria transmission when added to standard malaria control strategies in southern Malawi: study protocol for a clusterrandomised controlled trial. BMC Infect Dis. 2017;17:639.

27. malERA Consultative Group on Health Systems and Operational Research. A research agenda for malaria eradication: health systems and operational research. PLOS Med. 2011:8:e1000397.

28. malERA Consultative Group on Health Systems and Operational Research. An updated research agenda for health systems and policy research in malaria elimination and eradication. PLoS Med. 2017;14:e1002454.

29. Spiers A, Mzilahowa T, Atkinson D, McCall P. The malaria vectors of the lower Shire Valley, Malawi. Malawi Med J. 2002;14:4-7.

30. Mzilahowa T, Hastings IM, Molyneux ME, McCall PJ. Entomological indices of malaria transmission in Chikhwawa District, southern Malawi. Malar J. 2012;11:380.

31. Kabaghe AN, Chipeta MG, Terlouw DJ, McCann RS, van Vugt M, Grobusch MP, et al. Short-term changes in anemia and malaria parasite prevalence in children under 5 years during one year of repeated cross-sectional surveys in rural Malawi. Am J Trop Med Hyg. 2017;97:1568-75.

32. Lines J, Curtis C, Wilkes T, Njunwa K. Monitoring human-biting mosquitoes (Diptera: Culicidae) in Tanzania with light-traps hung beside mosquito nets. Bull Entomol Res. 1991:81:77-84.

33. Mboera L, Kihonda J, Braks M, Knols B. Short report: Influence of centers for disease control light trap position, relative to a human-baited bed net, on catches of Anopheles gambiae and Culex quinquefasciatus in Tanzania. Am J Trop Med Hyg. 1998;59:595-6.
34. Hartung C, Lerer A, Anokwa Y, Tseng C, Brunette W, Borriello G. Open data kit: tools to build information services for developing regions. In: Proceedings of the 4th ACM/IEEE International Conference on Information and Communication Technologies and Development; London, United Kingdom; 2010. p. 18.

35. Gillies M, Coetzee M. A supplement to the Anophelinae of Africa South of the Sahara. Publ S Afr Inst Med Res. 1987:55:1-143.

36. Scott JA, Brogdon WG, Collins FH. Identification of single specimens of the Anopheles gambiae complex by the polymerase chain reaction. Am J Trop Med Hyg. 1993;49:520-9.

37. Menger DJ, Omusula P, Wouters K, Oketch C, Carreira AS, Durka M, et al. Eave screening and push-pull tactics to reduce house entry by vectors of malaria. Am J Trop Med Hyg. 2016:94:868-78.

38. Waite JL, Lynch PA, Thomas MB. Eave tubes for malaria control in Africa: a modelling assessment of potential impact on transmission. Malar J. 2016;15:449.

39. Andriessen R, Snetselaar J, Suer RA, Osinga AJ, Deschietere J, Lyimo IN, et al. Electrostatic coating enhances bioavailability of insecticides and breaks pyrethroid resistance in mosquitoes. Proc Natl Acad Sci USA. 2015;112: 12081-6.

40. Mnyone LL, Lyimo IN, Lwetoijera DW, Mpingwa MW, Nchimbi N, Hancock PA, et al. Exploiting the behaviour of wild malaria vectors to achieve high infection with fungal biocontrol agents. Malar J. 2012;11:87.

41. Haddow AJ. The mosquito fauna and climate of native huts at Kisumu, Kenya. Bull Entomol Res. 2009;33:91-142.

42. McCann RS, Messina JP, MacFarlane DW, Bayoh MN, Gimnig JE, Giorgi E, et al. Explaining variation in adult Anopheles indoor resting abundance: the relative effects of larval habitat proximity and insecticide-treated bed net use. Malar J. 2017;16:288.

43. Mbogo C, Kabiru EW, Glass GE, Forster D, Snow RW. Khamala C, et al.Vectorrelated case-control study of severe malaria in Kilifi District, Kenya. Am J Trop Mede Hyg. 1999;60:781-5.

44. Busula AO, Takken W, Loy DE, Hahn BH, Mukabana WR, Verhulst NO. Mosquito host preferences affect their response to synthetic and natural odour blends. Malar J. 2015;14:133.

45. Jaleta KT, Hill SR, Birgersson G, Tekie H, Ignell R. Chicken volatiles repel hostseeking malaria mosquitoes. Malar J. 2016;15:354.

46. United Nations. Malawi Drought 2015-2016: The World Bank; 2016. https:// EconPapers.repec.org/RePEc:wbk:wboper:25781.

47. Tusting LS, Bottomley C, Gibson H, Kleinschmidt I, Tatem AJ, Lindsay SW, et al. Housing improvements and malaria risk in sub-Saharan Africa: a multicountry analysis of survey data. PLoS Med. 2017;14:e1002234.

48. Pinder M, Conteh L, Jeffries D, Jones C, Knudsen J, Kandeh B, et al. The RooPfs study to assess whether improved housing provides additional protection against clinical malaria over current best practice in The Gambia: study protocol for a randomized controlled study and ancillary studies. Trials. 2016;17:275.

Ready to submit your research? Choose BMC and benefit from

- fast, convenient online submission

- thorough peer review by experienced researchers in your field

- rapid publication on acceptance

- support for research data, including large and complex data types

- gold Open Access which fosters wider collaboration and increased citations

- maximum visibility for your research: over $100 \mathrm{M}$ website views per year

At BMC, research is always in progress.

Learn more biomedcentral.com/submissions 